\title{
Será que o formador sabe do que fala?*
}

\author{
Capucine Bremond ${ }^{1}$ \\ Conservatoire Nacional des Arts et Métiers (Paris, França)
}

Neste estudo, respondemos a uma demanda para formar tutores. Essa demanda insistia na necessidade de participar do desenvolvimento de competências e de explorar uma definição da tutoria. Abordamos essa formação a partir de dois aspectos: como educadores especializados em ciências da educação e como pesquisadores em análise das interações. Esses dois aspectos acompanhavam uma visão da formação na qual o formador, que é apenas um dos atores no processo, não traz seu saber como especialista. $\mathrm{O}$ que queremos examinar aqui é como o formador pode ficar dividido entre uma concepção da aprendizagem socioconstrutivista, que o coloca em posição de humildade, e as injunções que o situam como um especialista que detém uma parte essencial do saber. A especialização está inscrita nos fundamentos da relação entre os atores da aprendizagem. Uma prática socioconstrutivista suporia não somente que os "aprendizes" participassem ativamente na formação, mas também que o formador não permanecesse como dono da situação de troca na qual se inscreve - esse segundo aspecto raramente (ou nunca) é registrado no contexto atual. O que se espera do formador? Um mestre ou um ator? Se o formador deve concentrar o potencial formativo nas situações, mais do que se posicionar como dono da formação, eles precisam ocupar um lugar nutrido pelos desafios sociais e relacionais. Pensamos que, mesmo que o formador o desejasse, ele não poderia ser um simples mediador de saberes.

Palavras-chave: Formação, Análise das interações, Relação de lugares, Abordagem socioconstrutivista, Relação com o saber.

Le formateur sait-il de quoi il parle?

Nous avons répondu à une demande pour former des tuteurs. Cette demande insistait sur la nécessité de participer au développement de compétences et d'explorer une définition du tutorat. Nous avons abordé cette formation avec notre double casquette, enseignant spécialisé en sciences de l'éducation et chercheur en analyse des interactions. Cette double casquette allait de pair avec une vision de la formation où le formateur, acteur parmi d'autres, n'amène pas son savoir comme expert. Ce que nous voulons examiner ici c'est comment le formateur peut être tiraillé entre une conception de l'apprentissage socio-constructiviste, qui le positionne en humilité, et des injonctions qui le situent en expert détenant une partie essentielle du savoir. L'expertise est inscrite dans les fondements de la relation entre les acteurs de l'apprentissage. Une pratique socio-constructiviste supposerait non seulement que les "apprenants" participent activement à la formation mais aussi que le formateur ne reste pas maître de la situation d'échange dans laquelle il s'inscrit, second aspect rarement acté dans le contexte actuel, voir peut être même impratiquable. Qu'attend-on du formateur? Maitre ou acteur? Si le formateur doit participer à concentrer le potentiel formatif des situations plutôt que se positionner en maître de la formation, le formateur occupe une place nourrie par des enjeux sociaux et relationnels. Nous pensons que, même si il le souhaitait, il ne pourrait être un simple médiateur des savoirs.

Mots-clés: Formation, Analyse des interactions, Rapport de places, Approche socio-constructiviste, Rapport au savoir.

Do trainers know what they are talking about?

We responded to a request to train tutors. This request stressed the need to participate in skills development and to explore the definition of tutoring. We addressed this training with a double-hatted approach as teacher specialized in educational sciences and as interaction analysis researcher. This dual role was consistent with the conception of training where trainers, who are simply one of several actors, do not impart their knowledge as experts. What we wish to look at here is how trainers may be torn between socio-constructivist learning, which humbles them, and imperatives where they are considered as experts who have mastered the essence of knowledge. Expertise is part and parcel of the fundamentals of the relationship between persons involved in learning. Incorporating socioconstructivism would imply that not only would the "learners" play an active role in their training but that the trainers would not remain in command of the interactive situation they had established; a second aspect that is rarely applied in the current context and may even be deemed infeasible. So, what is expected of trainers? To be in command or to be actors? If trainers need to be involved in focusing the educational potential of situations rather than remaining in command of the training, then they hold a role nourished by social and relational challenges. And even if they wished to, they could not be just an advocate of knowledge.

Keywords: Training, Interaction analysis, Role relationship, Socio-constructivist approach, Relationship to knowledge.

* Publicado originalmente em: Nouvelle Revue de Psychosociologie, 15 (1), 241-252, 2013. DOI: 10.3917/nrp.015.0241

1 Maître de Conférences do CNAM/INETOP. 


\section{Introdução}

E m 2011, atendemos a uma demanda de formação da DAFOR (Delegação Acadêmica para Ca Formação), cujo foco era obter um melhor conhecimento da função tutorial de ensino e do desenvolvimento de competências ligadas a essa função.

Como professora-pesquisadora, essa demanda me mobilizou rapidamente, porque, além dos desafios socioeducativos evidentes que implicava, ela também colocava as modalidades da transmissão no centro do debate. Como ser educador e tutor? Esses dois atributos seriam indicativos de funções tão distintas? Será que nos comportemos de maneira diferente como educadores e como tutores? Além disso, como podemos ser formadores de tutores-educadores, quando nós mesmos somos educadores e formadores? Quais ressonâncias e quais distinções podemos experimentar entre esses atributos?

Como pesquisadora em análise das interações, ${ }^{2}$ trabalhando no campo da formação, respondi favoravelmente a essa demanda de intervenção, porque seu formulador ressaltou a necessidade de efetuar "uma formação relativa à entrevista, visando ajudar os educadores a explorar as competências e os conhecimentos exigidos para essa atividade em termos de postura e de repertório de gestos profissionais". Percebi, aqui, a vontade de explorar com o grupo uma definição da tutoria. Uma definição que estivesse conectada com as práticas efetivas, e não uma definição da qual eu seria detentora a priori. Trabalharíamos com uma abordagem socioconstrutivista (Vygotski, 1978) da formação, segundo a qual os saberes se elaboram pelos aprendizes nas discussões e na ação. Era a ocasião de tornar a interrogar, a partir de diversas modalidades de aprendizagem, uma visão de formação alimentada por pesquisas anteriores relativas à análise das interações.

\section{Interação e formação}

O que se exprime em uma interação é proveniente de uma configuração comunicativa que exclui a hipótese de que um indivíduo possa ser totalmente dono de um discurso. Garfinkel (1984), na esteira de Morris, ${ }^{3}$ enuncia que nunca existe ação pura, mas sempre uma interação. Falamos e agimos sempre para alguém, ou porque alguém realizou algo anteriormente. Nunca haveria discurso construído a partir de uma intencionalidade única, mas sempre a partir da conversação - que pode tomar as aparências de um discurso monológico -, ela mesma inscrita em um conjunto de conversações. Esse postulado subentende uma concepção de sujeito ao mesmo tempo movido pelo social - um sujeito que nunca fala sozinho e que pensa através de categorizações a que tem acesso - e um sujeito agindo sobre o social, por suas escolhas e por suas palavras. $^{4}$

Esse sujeito, que se manifesta essencialmente por meio da linguagem, ${ }^{5}$ é, ao mesmo tempo, ator e imbricado em uma série de "acontecimentos discursivos" 6 parcialmente imprevisíveis. Parece então impossível para o pesquisador linguista estabelecer uma gramática do discurso que seja inteiramente satisfatória. Nosso estudo sobre as "pequenas marcas do

2 Ver, a esse respeito: Kerbrat Orecchioni (1990, 1992, 1994), Traverso (1996), Vion (1992), Cosnier (1984).

3 Charles W. Morris, que foi o primeiro a utilizar o termo "prática", escreveu, em 1938, que "uma coisa só é um signo porque ela é interpretada como signo de algo por um intérprete".

4 Geroges Herbert Mead, iniciador do interacionismo simbólico.

5 Nós nos situamos aqui no quadro de uma abordagem semiótica do signo, por oposição a uma abordagem semiológica. Em semiótica, tudo o que faz sentido é signo, logo, é linguagem.

6 Ver, a esse respeito, Frédéric François (2005), que não fala de "encadeamento", mas de "movimentos" ou de "acontecimentos discursivos" mais ou menos previsíveis. 
discurso", tais como "bom, hein?, é isso aí...", visava a apreender os múltiplos níveis que estruturam o discurso, conferindo-lhe uma espessura que inibe qualquer vontade de impor a grade de análise de um especialista em sua superfície.

À leitura das marcas de um discurso oral, o pesquisador da análise das interações focaliza a interpretação: não sobre aquilo que o falante poderia querer significar, mas sobre o que foi retomado pelo interlocutor e deu lugar, portanto, a um encadeamento. A coerência do discurso só aparece quando cruzamos os níveis de análise e seguimos passo a passo os movimentos dos atores. Como formadores, será que podemos saber o que vai restar daquilo que queríamos significar quando mergulhamos na esfera das trocas, das discussões? Além disso, o que ocorrerá se arriscarmos dar sinais de escuta?

Se a formação for abordada como uma interação - o que ela de fato é -, sob vários aspectos, o formador é apenas um ator entre outros, e por isso não pode se posicionar como detentor de um saber como se tal saber não fosse essencialmente influenciado pelas discussões em que ele é enunciado. Nesse quadro, a formação só pode ser percebida como uma modalidade de intervenção que se inscreve em um processo em parte determinado pelo agente e em parte pelo objeto da ação (Dubost, 1987; Enriquez, 1992). Um formador que tem o objetivo de transmitir algo, e não de falar por si mesmo, deverá aceitar inscrever-se na interação, sem controlar os sentidos que suas falas suscitam no outro.

Laurent Filliettaz ressalta que as formações que integram o contexto da prática profissional se submetem às "características das situações ou do acoplamento ator-meio ambiente", o que "significa reconhecer, na prática em situação, propriedades de dinamismo, de imprevisibilidade e, nos atores, uma autonomia e uma responsabilidade importantes na construção das ações cotidianas e profissionais" (Filliettaz, 2009, p. 20). A isso queremos acrescentar que o caráter imprevisto e indeterminado das situações, das quais participam formadores e formados, ocorre logo que eles começam seus trabalhos, antes mesmo de pensar as situações profissionais a que a formação se refere e onde ela se inscreve.

Então um procedimento pedagógico consistiria preferencialmente em facilitar a emergência de situações e irrupções que concentram as ocasiões de um processo formativo heurístico (Bournois \& Bourion, 2009), sem que o formador possa ter certeza de que esse processo de formação seja efetivo em um instante determinado.

Já que o sentido se constrói em um espaço entre emissão e recepção, o formador tentará manter um espaço de diálogo que se interroga internamente. Ele agirá de maneira que os atores possam questionar seus saberes à luz de seu ambiente de trabalho e daquilo que eles depreendem de suas práticas mútuas.

Adotei essa abordagem quando acompanhei um grupo de cerca de vinte professorestutores durante oito encontros distribuídos ao longo de um ano escolar. Antes mesmo do começo dos encontros, pude me reunir com os educadores, em meia jornada, para avaliar a experiência do primeiro ano de tutoria, que estava em vias de terminar. Essa jornada de avaliação serviu para recolher suas necessidades de formação, mas também para iniciar um vínculo com os educadores antes do começo oficial na formação. Isso me pareceu necessário num contexto de reforma que instaurava a função tutorial no lugar das formações IUFM (Institutos Universitários de Formação de Professores).

Logo de início, esse tempo de trocas nos forneceu informações sobre a natureza do vínculo que íamos estabelecer com os professores. Tomei conhecimento do sentimento de isolamento que parece caracterizar sua função. Eles podem evoluir no espaço confinado da sala de aula, sem que sua função seja posta em questão. A formação em IUFM lhes aparecia como uma ocasião de circulação da palavra. No entanto, nessa ocasião os jovens colegas não poderiam mais se constituir como rede. 
Durante essas jornadas de avaliação, visivelmente os professores sentem prazer em (se) falar. Descobri neles uma propensão a deixar brotar a palavra livre, que não permite a reflexão sobre o que é enunciado por seus interlocutores. A fim de canalizar essa expressão que, a meu ver, "abre uma passagem como obstáculo de pensar e leva à privação da interioridade" (Leconte, 2011), fui levada, em seguida, a utilizar métodos ativos ao introduzir trocas "coelaborativas".

Uma vez em reunião, os momentos de debates contraditórios ${ }^{7}$ permitiram revelar incoerências de pensamento suscetíveis de gerar um conflito cognitivo. Quando um educador propôs estabelecer uma "grade de avaliação precisa e detalhada" para avaliar a prática dos educadores-estagiários, ele formulou um desejo coletivo (não era a primeira vez que esse desejo era expresso), o qual submetemos a debate. Discutindo sobre o conteúdo dessa possível grade de avaliação, os participantes concluíram: "como é impossível recuperar tudo o que é preciso lhes dizer", em seguida um deles afirmou "mas eu não posso thes dizer para fazer como eu; quando meu estagiário me observa com os alunos, ele deve pensar que sou louco". A argumentação desse debate tornou obsoleta a possibilidade de construir uma grade de avaliação precisa. Os participantes, no entanto, introduziram o caráter irredutível da distinção entre nossa boa prática e a boa prática de outrem. Ao afirmar o caráter não substituível das práticas, eles insistiram na necessidade de acompanhar os educadores-estagiários, observando suas práticas e suas interpretações das mesmas, em vez de lhes transmitir saberes baseados nas próprias experiências. Esse deslocamento foi reforçado pela presença de um educador que se expressava de maneira privilegiada, em tom normativo, enunciando certezas como esta: "não se ensina o que é ser um bom educador". Se a princípio suas palavras encontram eco no resto do grupo, com o tempo os participantes percebem seu caráter defensivo e se distanciam dele. Por isso mesmo, infelizmente, eles isolarão o participante, justificando em seguida sua saída e a coesão que se formou no resto do grupo.

Ao final, os momentos e as condições em que as transformações ocorrem nos escapam em parte. Se propusemos um debate contraditório, buscando instaurar um quadro favorável às transformações, pois o tema evocado nos parecia central nas representações da função tutorial, não sabíamos aonde essas trocas chegariam, nem mesmo se levariam a transformações pelo viés da técnicas de contradição.

Poderíamos ter sabido um pouco mais se não tivéssemos desencadeado o potencial formativo da situação e se não tivéssemos orientado prioritariamente o debate para uma ideia a ser transmitida. Nesse caso, teríamos nos posicionado assimetricamente na relação, a fim de continuar com o domínio da situação.

\section{O formador, "mestre" ou "ator"}

Se um sujeito só pode mestre daquilo que se enuncia nas trocas de que participa, ele pode se posicionar como mestre da situação de trocas pelo papel que se atribui e graças ao status que lhe é conferido. Sejam quais forem os modos de participação desenvolvidos em processo de formação, ninguém desconhece que os termos "formador" e "aprendiz" remetem a papéis assimétricos, um recebendo o que o outro inicia. Ora, os papéis que os atores em situação de formação se atribuem afetarão bem claramente o peso das trocas; logo, afetarão o conjunto dos processos de formação potencialmente em jogo.

7 Técnica de "colocar [alguém] no banco de interrogatório", que consiste em organizar controvérsias entre colegas (Peretti, 1991). 
Ser formador confere um status que autoriza a instaurar uma relação assimétrica de lugares no relacionamento. $\mathrm{O}$ formador é livre para decidir: "bem, agora, passaremos a outra coisa."

A psicossociologia contribuiu muito para questionar a distribuição dos papéis mestre/alunos (Ferry, 1962). Hoje se reconhece que os "aprendizes" devem tomar parte na elaboração do saber, para que haja apropriação (Lewin, 1947). Aliás, hoje o termo "aprendiz" é preferido aos termos "estagiário", "aluno" ou "estudante", que ratificam um status essencialmente passivo e tolerado, em vez de um papel ativo. É menos evidente admitir que formador e aprendiz estão presos em uma relação de lugares mutuamente obrigatórios (Goffman, 1973; Flahault, 1978). Uma elaboração partilhada supõe que o formador modifique, de seu lado, o lugar central que ocupa.

A priori, o formador detém o domínio da situação. Muitas vezes, ele procura ao menos reduzir a imprevisibilidade das situações em momentos-chave da formação. Ou poderá deixar que se instaure a troca e segurar as rédeas de maneira "solta", e não de uma forma "rígida", para retomar a metáfora de Laplantine (1996), deixando o jogo dos atores acontecer e a situação se modificar por si mesma. Mas, se opta por deixar a rédea mais solta, ele manterá a desordem sob um controle relativo e se autorizará a tomar decisões quando necessário.

L. Fillietaz vai mais longe, sugerindo que o formador que conduz a intervenção não tenha mais as rédeas, mas se posicione simetricamente com aqueles com quem interage:

Isso implica que as relações dos pesquisadores com os profissionais, ou dos formadores com os formados, não podem ser relações assimétricas, emanando de uma posição superior dos primeiros em relação aos segundos. Nas pesquisas, os profissionais contribuem de maneira central, de uma ou outra forma, à enquete sobre sua atividade e, nas formações, os formados contribuem, no sentido transformador de suas práticas. São esses próprios atores que detêm os saberes relativos às suas práticas, às chaves de sua análise e à sua transformação eficaz. Isso implica uma postura modesta do pesquisador como formador, sendo essa modéstia tanto uma atitude quanto um método (Fillietaz, 2009, p. 20).

Teil ressalta que considerar-se dono da situação torna difícil para o formador que intervém realizar uma reflexão sobre sua relação com o saber e com os sujeitos: "Como, sem renunciar a seu lugar de formador, deixar aparecer em si a dúvida, o questionamento sobre seu saber e seu saber-fazer, como aceitar não saber para abrir um espaço de palavra onde o formado poderá dizer e saberá que sua palavra será recebida, escutada, levada em consideração, discutida coletivamente, mesmo quando não for 'ortodoxa' "? (Teil, 2004, p. 108).

Mas querer que o formador se posicione simetricamente com os membros do grupo não quer dizer que ele deve simplesmente deixar a palavra com os "aprendizes". É preciso considerar o que isso acarreta nos diferentes níveis da relação entre os atores implicados.

Robert Vion (2006) chama de "institucionais" os lugares que os participantes ocupam, devido à situação que os reúne e que eles contribuem para manter. Em formação, ocupar reciprocamente os lugares de "formador" e de "formado" significa instaurar uma relação que contribui para a perenidade de uma situação. Segundo o autor, os lugares institucionais são retomados por outros lugares (modulares, subjetivos, discursivos, enunciativos) que cada um ocupa simultaneamente na troca. Mesmo ocupando o lugar institucional de "formador", eu poderia, por exemplo, fazer uma brincadeira e, em seguida, retomar um tom mais sério (mudanças subjetivas de lugares). A especificidade dos lugares institucionais é o fato de que sua modificação vai acarretar a reconfiguração total da interação. Portanto, os lugares asseguram a estabilidade e a manutenção da interação. Vejamos este exemplo: um médico pode parar uma consulta médica por um instante para conversar sobre as férias com seu paciente (mudança de

8 Foi-nos possível observar que a pessoa que enuncia: "bem”, para iniciar, para terminar ou para passar a um outro tempo das trocas, outorgando-se o direito de decidir a orientação comum e partilhada dos acontecimentos interacionais, será, de maneira quase sistemática, a única e mesma pessoa, seja qual for o número de participantes dessas trocas. 
lugares modulares e discursivos e mesmo subjetivos), sem, por isso, abandonar a consulta entre médico e paciente. Em compensação, Vion mostra, através de um exemplo, que, se um paciente se mostra muito experiente, do ponto de vista médico, ele ameaça os lugares institucionais em jogo na consulta, desestabilizando os fundamentos da relação que o liga a seu médico. Tendo isso em mente, como formadores, podemos iniciar um debate entre os participantes e nos retirar momentaneamente da troca, sem causar impacto nos lugares institucionais de "formador" e de "aprendiz". Dizer que o aprendiz é agente da formação, da mesma forma que o formador, supõe que os lugares institucionais sejam redistribuídos simetricamente. O que ocorre, de fato, na prática?

\section{O formador, homem de poder esperado em sua especialidade}

Tentamos deixar o máximo de lugar para a palavra dos participantes, elaborando nossas intervenções na base das discussões das quais tomamos nota. Cada sessão era seguida por uma avaliação proposta ao grupo no começo da sessão seguinte, preparando-se na mesma ocasião o objeto da nova sessão. Entretanto, conservamos e assumimos o status de experts. Em muitas ocasiões, pudemos sentir que se esperava do formador uma avaliação. Foi-nos impossível sustentar uma elaboração comum dos objetos em discussão e da orientação dos objetivos de aprendizagem.

Um primeiro nível de avaliação já fora solicitado por aqueles que me apresentaram a demanda inicial: que eu fosse soberana e decidisse uma parte do conteúdo da formação. Assim, a fim de que a qualidade de formação pudesse ser avaliada com base em elementos tangíveis, esperavam que eu propusesse um dispositivo de formação, de preferência em sala de aula, com objetivos claramente enunciados, com um desenvolvimento e conteúdos definidos. Um cuidado tecnicista de avaliação da qualidade (Hadji, 1989) leva inevitavelmente os solicitantes a encontrar meios de comparar normas estabelecidas entre as etapas da formação.

A especialização ou a experiência do formador também faz parte dos pressupostos da formação. Mesmo que o formador não dê sempre mostras de sua especialização, ele é percebido como tal. Mas qual é o seu lugar, se ele não estiver ali presente para trazer um mínimo de saberes? Mesmo se afastamos uma parte do problema, respondendo que a especialidade do formador não se reduz à transmissão de saberes relativos ao objeto da formação, não é fácil escapar a essa questão. $\mathrm{O}$ que os educadores com quem trabalhamos sabem pela experiência que têm na relação com os alunos é que, quando o mestre não é reconhecido e percebido como especialista pelos membros do grupo, é possível que ele não seja escutado. Como formadores, sentiremos isso, inclusive numa modalidade de intervenção em que cada sujeito deve ocupar um lugar, sem que deixemos transparecer uma especialização superior à dos outros. Na ocasião, pensei, e continuamos a pensar, que não seria pertinente "ensinar a lição" a educadores experimentados. No entanto, muito rapidamente, eles começaram a utilizar palavras de especialista difundidas por mim.

A especialização era igualmente esperada para responder à inquietação dos participantes. Em uma situação nova, as respostas, mesmo inadequadas, às vezes são bemvindas. Os educadores-tutores queriam que eu lhes ensinasse métodos para acompanhar eficazmente um treinamento de educadores-estagiários, ou seja, que lhes dissesse o que dizer. Eles queriam conhecer as artimanhas do ofício e saber como usá-las concretamente. Sua demanda era tão urgente que eles repetiam - e às vezes antecipavam - as inquietações dos educadores-estagiários, que pela primeira vez enfrentavam uma sala de aula. Cabia-me "ajudálos a ajudar". Respondi em parte a essa demanda, a fim de administrar tanto a urgência quanto o caráter emocional da situação, propondo que elaborássemos juntos alguns conselhos úteis 
para o início da tarefa. Paralelamente, introduzimos uma reflexão sobre a pertinência dessa demanda, deixando vir à tona as diferenças de práticas.

Notemos que os participantes, ao mesmo tempo que me pediam alguns truques prontos para aplicar, sem dúvida ficariam desapontados se eu me contentasse em fornecer isso a eles. Talvez eles retrucassem, afirmando que a realidade não permite aplicar o mesmo método ao conjunto das situações que eles encontravam. $O$ fato de formularem essa demanda não visava apenas a encontrar uma resposta que, embora lhes desse segurança, não teria sido suficiente. Minha maneira de proceder, ao levantar questões mais do que trazer respostas, logo de início não foi percebida como qualitativa. Além das avaliações da sessão, dispomos, como suporte de análise, de duas horas de gravação relativa à avaliação formadora do dispositivo. Nessas avaliações, fica evidente que os participantes "a princípio, não sabiam muito bem aonde ir". "Houve hesitações no meio das sessões, por não se saber aonde ir e, além disso, havia uma sensação de desestabilização." Dessa forma, balizamos cada início de sessão a partir da lembrança das elaborações progressivas e dos objetivos fixados em cada encontro. Mesmo assim, não consegui atenuar o sentimento de mal-estar ligado à imagem de criatividade (Marcelli, 2006) que se manifestava na formação. Os participantes disseram que "só mais tarde" entenderam o sentido e a direção do caminho percorrido. Pouco a pouco, instalou-se uma distância entre, de um lado, sua vontade de participar da construção da postura do educador principiante e, de outro, sua vontade de comunicar truques de ofício para que esses últimos saibam como agir. E, como consequência, eles não nos pediram mais truques para exercer a função de tutores.

Enfim, a imposição da intervenção provinha da instituição, na qual a formação é normalizada e regida por leis. No meu caso, o educador deveria avaliar os alunos a partir de grades de competências. Ele se encontra "investido do poder de verificar se os formados [neste caso, os alunos] possuem os conhecimentos e as aptidões que lhes são pedidos" (Teil, 2004, p. 108). Os educadores-tutores são também avaliadores dos educadores-estagiários. Devem preencher um relatório de avaliação, do qual dependerá a titularização desses últimos. Por trás dessas práticas, como lembra Teil, é o homem de poder que age, pois o formador tem também o papel de veicular uma mensagem de integração às normas da instituição.

\section{Conclusão}

Nossa palavra de especialista era esperada em vários níveis. Resistimos em parte a essa espera, na expectativa de participar, como por ressonância, da reelaboração da postura do tutor.

Era exatamente essa ressonância entre os níveis de atividade que me interessava explorar neste estudo. Penso ter podido, então, identificar alguns deslocamentos. No princípio, os educadores diziam não compreender como podiam contribuir com um educador-estagiário que tinha dificuldades para manter sua classe calma apesar de ter saído de uma formação dedicada à gestão de classes. Em seguida, eles disseram que os problemas com o grupo são apenas o sintoma, que precisava ser discutido, de uma dificuldade particular do educador. A posterior mudança em sua maneira de reagir testemunha uma tomada de distância da palavra do "especialista", que evitaria, no nascedouro, os problemas pré-repertoriados. Introduziam-se, assim, as questões da interação. Ao tratar das situações-problema com os educadoresestagiários na classe, eles tiveram oportunidade de, na mesma ocasião, se colocar no papel de educadores psicossociólogos (Gilles Ferry, 1962).

Mas o indicador mais forte era, sem dúvida, a dificuldade dos educadores-tutores em ter clareza de que a formação visava a facilitar a missão do educador-estagiário e não a ajudar 
os alunos pelos quais esses últimos eram responsáveis. Muito frequentemente os conselhos enunciados se dirigiam aos alunos. Era preciso lembrar-lhes de que eles deveriam dirigir-se ao educador-estagiário e não diretamente aos alunos. Assim, o direito ao erro do educadorestagiário ficava fora de questão, e a palavra do "especialista" se impunha, a fim de mitigar as dificuldades já no nascedouro: "é preciso dar-lhe conselhos para serenar os alunos; é preciso dar-lhe munição para que ele controle sua classe"; "fracassar no curso, tudo bem, mas se dar mal na primeira aula é a catástrofe." Essas falas, não destituídas de sentido, repetiam-se com insistência. O momento em que se deram conta de que deveriam trabalhar com o educadorestagiário, após eu lhes dizer que o educador-estagiário deve se questionar sobre por que o grupo reage mal, marcou a mudança para um novo posicionamento na relação mestre-tutoraluno.

Por isso, embora o título deste artigo possa dar a entender que o formador não sabe necessariamente do que fala, ele não remete à realidade da prática. Dizer que o formador limita-se a questionar os saberes dos aprendizes, situando-os no ambiente de trabalho, a fim de aclarar suas incoerências, seria desprezar o papel indubitavelmente ativo do formador. $O$ discurso do formador é permeado pela presença daqueles a quem se dirige diretamente. Esse discurso é também atravessado por múltiplas vozes anteriores, a sua e as da instituição da qual ele representa a continuidade. Como observa Teil, "não é porque essa dimensão do formador, como homem do poder, é pouco evidenciada, que ela não existe ou que não gera efeitos perversos; e estes são mais graves à medida que permanecem não repertoriados nem analisados" (Teil, 2004, p. 109). Sem dúvida, é nefasto mascarar as vozes que atravessam nosso discurso, colocando-nos como receptáculo objetivo dos dizeres alheios. Para o formador, reintroduzir a dimensão da relação com o saber significa posicionar-se como sujeito ativo, formador, mas humilde, que não pretende ser um simples catalisador. É também aceitar ocupar um papel que condiciona as trocas, em vez de assumir uma posição de absoluta neutralidade.

Dizer que nosso olhar relativo à dimensão das discussões num contexto de formação estava balizado por nossas pesquisas em análise das interações era uma maneira de fazer que se ouvisse uma voz singular, em vez de querer colocar resultados provisórios. Apresentava-se ali um convite ao diálogo, fosse ele intra ou intersubjetivo. Da mesma forma, poderíamos imaginar um formador que, de acordo com sua subjetividade, dispóe-se a ensinar ao mesmo tempo que contribui para elaborar novos saberes. Se sua posição será de "especialista" ou de mediador, isso dependerá não apenas do método que ele escolher, mas também da recepção que ele encontrar e à qual deve se ajustar.

\section{Referências}

Bournois, F. \& Bourion, C. (2009). L'approche heuristique dans la formation des responsables. Revue Internationale de Psychosociologie, 37 (15), 17-20.

Cosnier, J. \& Brossard, A. (1984). La communication non verbale. Neuchâtel: Delachaux et Niestlé.

Dubost, J. (1987). L'intervention psychosociologique. Paris: PUF.

Enriquez, E. (1997). Les jeux du pouvoir et du désir dans l'entreprise. Paris: PUF.

Enriquez, E. (1992). L'organisation en analyse. Paris: PUF.

Ferry, G. (1962). Mutation de la fonction enseignante. Présentation au Colloque sur Pédagogie et Psychologie des Groupes. Paris: Association pour la Recherche et l'Intervention Psycho-Sociologiques.

Fillietaz, L. (2009). Des liens entre travail et formation: vers une nouvelle épistémologie? In M. Durand \& L. Fillietaz (Orgs.), Travail et formation des adultes (pp. 1-34). Paris: PUF.

Flahault, F. (1978). La parole intermédiaire. Paris: Seuil.

François, F. (2005). Interprétation et dialogue chez des enfants et quelques autres. Lyon: ENS. 
Garfinkel, H. (1984). Qu'est-ce que l'ethnométhodologie? Arguments Ethnométhodologiques, 3, 54-99.

Goffman, E. (1973). La mise en scène de la vie quotidienne. Paris: Minuit.

Hadji, C. (1989). L'évaluation règles du jeu. Paris: ESF.

Kerbrat Orecchioni, C. (1990/1992/1994). Les interactions verbales (3 tomes). Paris: Armand Colin.

Laplantine, F. (1996). La description ethnographique. Paris: Nathan.

Leconte, C. (2011). Analyse des pratiques et processus de subjectivation en situation professionnelle. Nouvelle Revue de Psychosociologie, 1, 53-66.

Lewin, K. (1947). Frontiers in groups dynamics. Human relations, 1 (1), 5-41.

Morris, C. (1938). Foundations of the theory of signs. International Encyclopedia of Unified Science, 63-75.

Marcelli, D. (2006). La surprise, chatouille de l'âme. Paris: Albin Michel.

Peretti, A. (1991). Organiser des formations. Paris: Hachette.

Teil, P. (2004). Le formateur et le pouvoir, Empan, 56 (4), 106-109.

Traverso, V. (1996). La conversation familière. Lyon: PUL.

Vion, R. (2006). Séquentialité, interactivité et instabilité énonciative, Cahiers de Praxématique, 25-50.

Vion, R. (1992). La communication verbale. Paris: Hachette.

Vygotsky, L. S. (1978). Mind in society. Cambridge, MA: Harvard University Press.

\section{Endereço para correspondência}

capucine.bremond@cnam.fr 